\title{
Cutaneous leishmaniasis a neglected tropical disease: community knowledge, attitude and practices in an endemic area, Northwest Ethiopia
}

Helina Fikre Tamiru ${ }^{1,2}$, Yohana James Mashalla ${ }^{1,3^{*}}$ (D) Rezika Mohammed ${ }^{2}$ and Gloria Thupayagale Tshweneagae ${ }^{1}$

\begin{abstract}
Background: Cutaneous leishmaniasis is one of the neglected tropical diseases in the Ethiopian highlands and studies on assessment of knowledge, attitude and practice of the community in endemic areas are scanty. The study aimed to assess the knowledge, attitude towards cutaneous leishmaniasis and treatment seeking practices in people living in the endemic highlands areas in the Northwest, Ethiopia and to provide evidence-based information to guide development of appropriate interventions to reduce the impact of cutaneous leishmaniasis on communities.

Methods: Quantitative cross-sectional study was conducted in cutaneous leishmaniasis endemic districts (woredas) using a semi structured questionnaire. Households were randomly selected according to probability proportional to size of households in each enumeration area. Systematic random sampling of eligible households was based on the number of households recorded during listing of households. Descriptive statistics was used to describe numerical data, organise and summarise the data in a manner that gave meaning to the numerical form. Frequency tables were used to show descriptive analysis and regression analysis was used to determine correlation between variables.

Results: Majority of respondents $321(78.7 \%)$ lived in rural areas, age ranged between 18 and 85 years and most were farmers. Illiteracy was high (47.6\%) among respondents and majority 358(87.8\%) had seen patients with CL. Less than quarter (21.6\%) had heard about sand flies and knowledge on the peak transmission period was low (46.3\%). About 192 (47.1\%) of the respondents indicated disfiguring lesions were the major clinical presentations, less than half 55(27.5\%) of urban residents believed CL was treatable compared to 145(72.5\%) of rural residents $(P<0.001)$. Traditional medicines were indicated as best treatment option by 209(51.2\%) compared to 114(27.9\%) for modern treatment. Major factors influencing treatment options included accessibility to treatment facilities, distance and short duration of treatment. Participants expressed negative experiential attitude and perceived control towards modern treatment because of inaccessibility and distance from where modern treatment is provided.
\end{abstract}

Conclusion: Priority should be given to primary prevention and appropriate awareness campaigns on lesion recognition. Information on modern treatment should be intensified.

Keywords: Cutaneous leishmaniasis, Knowledge, Attitude, Practice, Ethiopia

\footnotetext{
* Correspondence: yohana.mashalla@mopipi.ub.bw

${ }^{1}$ Department of Health Studies, University of South Africa, Pretoria, South

Africa

${ }^{3}$ Faculty of Medicine, University of Botswana, Gaborone, Botswana

Full list of author information is available at the end of the article
}

(c) The Author(s). 2019 Open Access This article is distributed under the terms of the Creative Commons Attribution 4.0 International License (http://creativecommons.org/licenses/by/4.0/), which permits unrestricted use, distribution, and reproduction in any medium, provided you give appropriate credit to the original author(s) and the source, provide a link to the Creative Commons license, and indicate if changes were made. The Creative Commons Public Domain Dedication waiver (http://creativecommons.org/publicdomain/zero/1.0/) applies to the data made available in this article, unless otherwise stated. 


\section{Background}

Leishmaniasis is a tropical disease caused by a vectorborne protozoan parasite of the genus Leishmania and transmitted by bites of infected female sandflies (Phlebotomus and Lutzomyia). About 98 countries of the world are affected with estimated 350 million people being at risk. With a global prevalence of approximately 12 million people and annual incidence 2-2.5 million cases, the disease is endemic in many countries [1]. The clinical manifestation of leishmaniasis is influenced by the infected vector resulting in three distinct presentations including cutaneous leishmaniasis (CL), mucosal involvement (MCL) and systemic visceral involvement (VL) [2]. Worldwide, Cutaneous leishmaniasis is the most common form of leishmaniasis and approximately 90\% occurring in the Middle East and southern America countries [3]. More than 20 types of leishmania species are responsible for CL. Immunological studies have classified Leishmania parasites into Old World species including Leishmania major, Leishmania infantum and Leishmania tropica that are commonly found in the Middle East, Mediterranean basin and the Horn of Africa and the New World species commonly found in the southern America countries [4].

Ethiopia, on the Horn of Africa is among the countries with a high burden of cutaneous leishmaniasis estimated to range from 20,000 to 30,000 cases per year and the disease is endemic in the highland areas with an elevation of 1400-3175 $\mathrm{m}$ above sea level [5]. According to a systematic review and meta-analysis of leishmaniasis in Ethiopia [6] the most dominant type of leishmaniasis is visceral leishmaniasis (VL) much more devastating in the northern part of the country [7]. The major concern regarding VL is its high fatality rate which may rise to up to $100 \%$ among non-treated compared to only $10 \%$ among treated patients [8]. Leishmania major has also been reported in the country [9]. Leishmania aethiopica is the main cause of $\mathrm{CL}$ in Ethiopia causing the most severe forms of CL such as diffuse CL with multiple skin lesions characterised by non-ulcerating papular, nodular and plaque involving most parts of the body [10]. Three clinical presentations of $\mathrm{CL}$ have been reported in the country including localised cutaneous leishmaniasis which is characterised by localised papular or nodular lesion at the site of the sand-fly bite. The ulcer is usually painless, pink, and round with well-defined raised edges and in some cases could be self-limiting. Also reported in the country is muco-cutaneous leishmaniasis characterised by mucosal (nasal, oral, pharynx, larynx) involvement either by direct bite on the mucosal surface or by extension of the localized cutaneous leishmaniasis [11]. Previous studies have indicated that disfigurement due to CL has both socially and psychologically impacts causing anxiety, stress, depression and low quality of life which ultimately impacts on individual's economic productivity.
Therefore, treating cases and limiting potential scar formation and disfigurement are recommended measures in reducing the impact of $C L[12,13]$.

Direct relationship between awareness of the population at risk of a disease and adoption of preventive measures has been reported [14]. Most studies on CL in Ethiopia have focused on assessing safety and effective treatment of CL and have reported that Sodium Stibogluconate (SSG) remains the first line drug of choice. The treatment outcome however, is usually poor as most patients report for treatment several months (average 19) from commencement of symptoms and treatment which require SSG injections for two or more months [15]. Few health facilities in the country that have the capacity to diagnose and treat CL with the majority located in cities far from endemic areas complicates CL health promotion and control measures in these communities. Therefore, this study aimed to assess the knowledge, attitude and practices of the communities towards CL in the endemic areas in Gondar zone with a view to provide evidence-based data that will contribute to the success of leishmaniasis prevention and control programmes.

\section{Methods}

A quantitative, descriptive cross-sectional survey was conducted to assess the level of knowledge, attitude and practices about CL among people living in four endemic areas in northwest, Ethiopia.

\section{Study setting}

Located on the north western and central part of Ethiopia, Amhara region consists of 7 zones and 105 districts [16]. Four districts from Northwest Ethiopia including Gondar, Lay Gayint, Maksegnit and Armachiho were selected in this study. Selection of the districts was purposively done based on the case burden registered at the Leishmaniasis Research and Treatment Centre (LRTC), Gondar University Hospital where most patients from northwest Ethiopia visit for diagnosis and treatment of both cutaneous and visceral leishmaniasis. The Centre was established in collaboration with the Drug for Neglected Diseases Initiative and University of Gondar for research and treatment of leishmaniasis. Each district had an average of 30 kebeles or villages and each kebele had an average of 700 households. Each household had an estimated population of 5 people living together.

\section{Study design and sampling procedures}

Quantitative cross-sectional study was conducted in cutaneous leishmaniasis endemic districts using a semi structured questionnaire. The study was carried out in December 2017. Purposive sampling technique was used to select 15 kebeles giving a total of 10,500 accessible households. The estimated population in each kebele 
ranged from 3500 to 4000; therefore, an estimated 52, $500-60,000$ population was accessible in the study. Twostage cluster sampling approach was used to determine the sample size. In the first stage, 15 sample points (Enumeration Areas, EAs) were selected independently from all the strata with Probability Proportional to Size (PPS) of households using the 2007 Population and Housing Census data [17]. Since the prevalence of CL was not known, 50\% prevalence of CL was used to determine the sample size. Simple random sampling was used to select participants into the study. Both male and female adults aged 18 years and above were eligible for inclusion in the study and the calculated sample size was 384. A 6\% design defect and non-response rate was added to the calculated sample size. Therefore, total of 408 participants took part in the study.

\section{Data collection}

The data collection instrument (questionnaire) was designed by the investigator. Prior to data collection, the questionnaire was pre-tested on eight persons who had similar characteristics but were not part of the study population. Thirty (30) health extension workers were employed to administer the questionnaires after being trained on data collection procedures and ethical consideration.

\section{Data analysis}

Descriptive statistics was used to organise, describe and synthesise the data in order to facilitate insight about knowledge, attitude and practices on CL. Inferential statistics to test relationships between the variables and demographic factors was also used and the level of significance $(p=0.25)$ as two-tailed test was employed. Epi info 7 was used for descriptive statistics and SPSS version 16 was used to further analyse the data. Regression analysis was used to determine the association between variables and frequency tables were used to show descriptive analysis results.

\section{Ethical consideration}

Ethical clearance (Ref: HSHDC/784/2017) was obtained from the Research and Ethics Committee of the Department of Health Studies of the University of South Africa and Institutional Review Board of University of Gondar, Ethiopia (O/V/P/RCS/05/57/2017). Permission to conduct the study in the districts was obtained from the local Administrative Departments. All participants in the study were subjected to a consent form after the purpose and the procedures were clearly explained to them to a level that they comprehended and willingly consented. The names of participants were not entered on the research instrument and there was no link between the participant and the collected data.

\section{Results}

Sociodemographic characteristics of the study population Four hundred eight (408) adults participated in the study; 234.57.4\%) and 174 (42.7\%) were female and male respectively. Majority $321(78.7 \%)$ were living in rural areas and $87(21.3 \%)$ lived in urban areas. Age ranged between 18 and 85 years; the mean and median ages were 36 and $35-45$ years respectively. Most participants 255 (62.5\%) engaged in farming, 41(10.1\%) were government employees and 55(13.5\%) were self-employed. Illiteracy was high 194(47.6\%), 21(5.2\%) could read and write, 114(27.9\%) and 59(14.5\%) had completed primary and secondary education respectively. Only $20(4.9 \%)$ had attained higher education qualifications (Table 1).

\section{Knowledge about $\mathrm{CL}$, the vector, clinical presentation and sources of information}

Table 2 summarises participant's knowledge about CL, the vector, clinical presentations and sources of information about CL. Most participants, 358(87.8\%) had seen CL previously and $315(77.9 \%)$ recognised CL as one of the health problems in the area. CL was locally described as "Setie" meaning female softer swollen lesions and "Wondie" meaning male rough and hard lesions that do

Table 1 Sociodemographic characteristics of the study participants in Northwest, Ethiopia

\begin{tabular}{lll}
\hline Variable & Frequency & Percent (\%) \\
\hline Age & 133 & 32.6 \\
$18-30$ & 140 & 34.3 \\
$31-40$ & 90 & 22.1 \\
$41-50$ & 31 & 7.6 \\
$51-60$ & 14 & 3.4 \\
$\geq 61$ & & \\
Gender & 234 & 57.4 \\
Female & 174 & 42.7 \\
Male & & \\
Education level & 21 & 5.2 \\
Read and write & 114 & 27.9 \\
Primary & 59 & 14.5 \\
Secondary & 20 & 4.9 \\
Tertiary & 194 & 47.6 \\
Illiterate & & \\
Occupation & 255 & 62.5 \\
Farmer & 10.1 \\
Government employee & 41 & 7.4 \\
House wife & 30 & 13.5 \\
Private & 55 & 2.9 \\
Student & 12 & 3.7 \\
Unemployed & 15 & \\
\hline
\end{tabular}


Table 2 Knowledge about $C L$ among participants resident in $\mathrm{CL}$ endemic areas in northwest, Ethiopia

\begin{tabular}{lll}
\hline Variables & Frequency & Percent \\
\hline Seen a cutaneous leishmaniasis & & \\
No & 50 & 12.3 \\
Yes & 358 & 87.8 \\
Signs of CL & & \\
Painful lesion/disfiguring & 34 & 8.3 \\
Painless/disfiguring & 9 & 2.2 \\
Painful skin lesion & 103 & 25.3 \\
Disfiguring skin lesion & 149 & 36.5 \\
Fever & 4 & 0.9 \\
Other & 5 & 1.2 \\
I don't know & 55 & 13.5
\end{tabular}

Have you seen a person with $\mathrm{CL}$ at your vicinity?

$\begin{array}{ll}\text { Yes } & 315 \\ \text { No } & 91\end{array}$

Which gender is most affected by $\mathrm{CL}$ ?

$\begin{array}{lll}\text { Both } & 79 & 19.4 \\ \text { Female } & 71 & 17.4 \\ \text { Male } & 135 & 33.1 \\ \text { I don't know } & 121 & 29.7\end{array}$

Indicate which parts of the body are mostly affected by $\mathrm{CL}$

$\begin{array}{lll}\text { Face } & 324 & 79.4 \\ \text { I don't know } & 69 & 16.9\end{array}$

No specific site $\quad 15$

Which age groups are most affected by $\mathrm{CL}$ ?

$\begin{array}{ll}\text { Adult } & 68 \\ \text { Adult/elderly } & 1 \\ \text { Children } & 29 \\ \text { Elderly } & 22 \\ \text { All age } & 225\end{array}$

I don't know 62

How is CL transmitted?

$\begin{array}{lll}\text { By mosquito bite } & 24 & 5.9 \\ \text { Sand fly } & 93 & 22.8 \\ \text { Air droplet } & 5 & 1.2 \\ \text { Direct contact } & 39 & 9.6 \\ \text { Other } & 110 & 26.9 \\ \text { I don't know } & 137 & 33.6\end{array}$

Have you heard of sand fly?

$\begin{array}{lll}\text { Yes } & 87 & 21.3 \\ \text { No } & 321 & 78.7\end{array}$

Does Sand fly transmit diseases?

$\begin{array}{lll}\text { No } & 109 & 26.7 \\ \text { Yes } & 219 & 53.7\end{array}$

Table 2 Knowledge about $C L$ among participants resident in $\mathrm{CL}$ endemic areas in northwest, Ethiopia (Continued)

\begin{tabular}{lll}
\hline Variables & Frequency & Percent (\%) \\
\hline I don't know & 80 & 19.6 \\
What types of diseases are transmitted by sandfly? & \\
Diarrhoea & 75 & 18.4 \\
Fever & 26 & 6.4 \\
Cutaneous leishmaniasis & 153 & 37.5 \\
Gastritis & 4 & 0.9 \\
Skin lesion & 64 & 15.7 \\
I don't know the name & 19 & 4.7 \\
I don't know & 11 & 2.7 \\
Where do sandfly breed? & & \\
Building ruins & 2 & 0.5 \\
Farmland & 4 & 0.9 \\
In house & 3 & 0.7 \\
Unhygienic place & 35 & 8.6 \\
Waste disposal sites & 36 & 8.8 \\
Other & 58 & 14.2 \\
I don't know & 270 & 66.2
\end{tabular}

What time do sand flies bite?

$\begin{array}{lll}\text { Dawn/dusk \&midnight } & 31 & 7.6 \\ \text { Dawn/dusk day } & 7 & 1.7 \\ \text { Day/mid night } & 1 & 0.3 \\ \text { Dawn/dusk } & 48 & 11.8 \\ \text { Day } & 20 & 4.9 \\ \text { Mid night } & 41 & 10.1 \\ \text { All the time } & 23 & 5.6 \\ \text { I don't know } & 237 & 58.1\end{array}$

Which season of the year is peak for $\mathrm{CL}$ ?

$\begin{array}{lll}\text { Summer and winter } & 7 & 1.7 \\ \text { Winter and spring } & 3 & 0.7 \\ \text { Winter \& spring \& summer } & 1 & 0.3 \\ \text { Autumn only } & 31 & 7.6 \\ \text { Summer and spring } & 2 & 0.5 \\ \text { Summer/spring/autumn } & 6 & 1.5 \\ \text { Spring only } & 36 & 8.8 \\ \text { Summer only } & 88 & 21.6 \\ \text { Winter only } & 26 & 6.4 \\ \text { All year round } & 19 & 4.7 \\ \text { I don't know } & 189 & 46.3\end{array}$

What are your sources of information on $\mathrm{CL}$ ?

$\begin{array}{ll}\text { TV and radio } & 2 \\ \text { Radio only } & 9 \\ \text { TV only } & 4 \\ \text { Community health education } & 6\end{array}$


Table 2 Knowledge about $C L$ among participants resident in $\mathrm{CL}$ endemic areas in northwest, Ethiopia (Continued)

\begin{tabular}{lll}
\hline Variables & Frequency & Percent (\%) \\
\hline Community centre & 225 & 55.2 \\
Health education (Schools) & 61 & 14.9 \\
Newsletters & 3 & 0.7 \\
No sources of information & 97 & 23.8 \\
Other sources & 1 & 0.3 \\
\hline
\end{tabular}

not heal easily. Almost one third 108(26.7\%) described $\mathrm{CL}$ as a disease characterised by lesions mainly affecting the face and 57(13.9\%) described it as a disease with very ugly disfiguring lesions that may even deform the nose causing disability. About $10 \%$ believed the disease is caused by bats and small percentages related the disease to lack of hygiene and punishment from God. Education did not associate significantly with the knowledge about the disease while location (rural vs urban) associated significantly $(P<0.025)$ with the knowledge about $\mathrm{CL}$ with rural residents being more knowledgeable about the disease than urban residents (Tables 3 and 4). Less than quarter 88(21.6\%) had heard about sand fly of which 57(13.97\%) and 51(12.5\%) indicated that waste disposal and unhygienic places respectively were breeding sites for sand flies. Majority 237(58.1\%) did not know the time when sand flies bite while $8(21.6 \%)$ and $70(17.2 \%)$ indicated at dawn/dusk and midnight respectively.

Almost half of the participants (46.3\%) did not know the peak season for CL transmission while $88(21.6 \%)$, 38(9.3\%), 54(13.2\%) indicated summer, autumn and spring respectively. Almost 19(4.7\%) indicated that transmission was common all year round. More than half $237(58.1 \%)$ of the participants knew that sand flies transmit diseases compared to 189 (46.3\%) who did not think that sand flies transmit any diseases. Among those who knew that sand flies transmit diseases, 153(37.5\%) indicated that the fly can transmit CL. In addition, 24(5.9\%) and 39(9.6\%) believed CL was transmitted by mosquitoes and through direct contact with affected persons respectively. Almost 2.0\% (1.96\%) indicated bat's urine or sputum were causes of CL. Other diseases thought to be transmitted by sand flies were diarrhoeal diseases 75(18.4\%), other skin lesions 64(15.7\%) and gastritis about $4(1.0 \%)$. With respect to clinical presentations, majority 295(72.3\%) described CL based on the location and clinical appearance. About 192(47.1\%) indicated disfiguring lesions as the main clinical presentation of CL, 137(33.6\%) as painful lesions, $9(2.2 \%)$ as painless lesion. Another 55(13.5\%) did not know of any symptoms of CL. Over half 225(55.1\%) received information about CL from the community and 97(23.8\%) did not have sources of information about the disease. Other sources were schools (health education) $61(14.9 \%)$ and community health education $6(1.5 \%)$.

\section{Attitude towards of $\mathrm{CL}$}

Over half (51.7\%) of the participants with tertiary education had seen patients with CL followed by those with primary level education 106(29.6\%). Among participants who had seen CL, 337 (82.6\%) indicated that the disease was a serious problem in their area. Cosmetic consequences as reasons for seriousness of the disease was stated by 275 (67.4\%), disability 190(46.6\%) and 74(18.1\%) indicated stigma. However, there was no statistically significant association $(p>0.025)$ between the level of education and attitude towards CL except for the knowledge on preventive measures which significantly associated $(p=0.014)$ with level of education (Table 3).

Attitude towards treatment and treatment options for CL Majority 294(82.1\%) of rural residence had seen patients with CL compared to $64(17.9 \%)$ of the urban residents. However, no statistical difference $(P=0.269)$ was observed whether the participants had heard about sand fly. While majority of the participants were concerned that $\mathrm{CL}$ is a serious condition less than half 55(27.5\%) of the urban residents believed that $\mathrm{CL}$ is treatable compared to $145(72.5 \%)$ among rural residents $(P<0.000)$. Over half $(68.3 \%)$ of the participants indicated that most patients with CL received traditional medicines from traditional healers and traditional medicines as the best treatment option was indicated by $209(51.2 \%)$ who believed so because of easy accessibility compared to 114(27.9\%) who indicated modern medicines as their best treatment option. The reasons given for the choice of modern treatment as the best treatment option included easy accessibility 22(5.4\%), the only option $53(13.0 \%)$ and short duration of treatment 26(6.4\%). Only 50(12.3\%) knew names of modern medicines for treating CL among which 33(8.1\%) indicated that medicine could be obtained from hospitals and the remaining $4.2 \%$ from health centres. There was no statistically significant association $(P>0.025)$ between the level of education and attitude towards treatment of CL (Table 3) but attitude towards treatment of CL significantly $(P<$ $0.025)$ associated with location with rural residents showing more concerns (Table 4).

\section{Knowledge of preventive measures of $\mathrm{CL}$}

Among the total participants, 300(73.5\%) selected one or more preventive measures while $108(26.5 \%)$ did not know of any preventive measures against the infecting agent. Majority of the participants $171(41.9 \%)$ and $129(31.6 \%)$ indicated hygiene and bed nets respectively. Health education was stated by $76(18.6 \%)$ as necessary in 
Table 3 Association between knowledge and attitude towards $C L$ and the education levels among residents in $C L$ endemic areas in northwest Ethiopia

\begin{tabular}{|c|c|c|c|c|c|c|}
\hline \multirow[t]{2}{*}{ Questions/responses } & \multicolumn{4}{|c|}{ Education levels frequency and percentages } & \multirow[t]{2}{*}{$x^{2}$} & \multirow[t]{2}{*}{$P$-value } \\
\hline & Primary n (\%) & Secondary n (\%) & Tertiary n (\%) & Illiterate n (\%) & & \\
\hline \multicolumn{7}{|c|}{ Have you ever seen patients with CL? } \\
\hline No & $81(6)$ & $8(16)$ & $4(8)$ & $30(60)$ & \multirow[t]{2}{*}{4.694} & \multirow[t]{2}{*}{0.196} \\
\hline Yes & 106(29.6) & $51(14.2)$ & $16(4.5)$ & 185(51.7) & & \\
\hline \multicolumn{7}{|l|}{ Have you heard of sand fly? } \\
\hline No & $88(27.4)$ & $44(13.7)$ & $16(5)$ & 173(53.9) & \multirow[t]{2}{*}{1.172} & \multirow[t]{2}{*}{0.76} \\
\hline Yes & 26(29.9) & 15(17.2) & $4(4.6)$ & $42(48.3)$ & & \\
\hline \multicolumn{7}{|l|}{ Do sand flies transmit $\mathrm{CL}$ ? } \\
\hline No & $24(22)$ & $12(11)$ & $5(4.6)$ & $68(62.4)$ & \multirow[t]{3}{*}{7.42} & \multirow[t]{3}{*}{0.284} \\
\hline Yes & $69(31.5)$ & $36(16.4)$ & $10(4.6)$ & $104(47.5)$ & & \\
\hline I don't know & $21(26.2)$ & 11(13.8) & $5(6.2)$ & $43(53.8)$ & & \\
\hline \multicolumn{7}{|l|}{ How is CL transmitted? } \\
\hline I don't know & $32(23.4)$ & $16(11.7)$ & $9(6.6)$ & $80(58.4)$ & \multirow[t]{5}{*}{11.96} & \multirow[t]{5}{*}{0.449} \\
\hline Direct contact and air droplets & $11(25)$ & $6(13.6)$ & $1(2.3)$ & $26(59.1)$ & & \\
\hline Sand fly & $26(28)$ & 18(19.4) & $6(6.5)$ & $43(46.2)$ & & \\
\hline Mosquitoes & $6(25)$ & $4(16.7)$ & $\mathrm{O}(0.0)$ & $14(58.3)$ & & \\
\hline Others & $39(35.5)$ & 15(13.6) & $4(3.6)$ & $52(47.3)$ & & \\
\hline \multicolumn{7}{|l|}{ Is $\mathrm{CL}$ a serious disease? } \\
\hline No & $6(30)$ & $1(5.0)$ & $0(0.0)$ & $13(65)$ & \multirow[t]{3}{*}{7.939} & \multirow[t]{3}{*}{0.243} \\
\hline Yes & $99(29.4)$ & $49(14.5)$ & $19(5.6)$ & $170(50.4)$ & & \\
\hline I don't know & $9(17.6)$ & $9(17.6)$ & $1(2)$ & $32(62.7)$ & & \\
\hline \multicolumn{7}{|l|}{ Is $\mathrm{CL}$ a treatable disease? } \\
\hline No & $31(30.4)$ & $12(11.8)$ & $4(3.9)$ & $55(53.9)$ & \multirow[t]{3}{*}{11.67} & \multirow[t]{3}{*}{0.07} \\
\hline Yes & $58(29)$ & $33(16.5)$ & $15(7.5)$ & $94(47)$ & & \\
\hline I don't know & 25(23.6) & $14(13.2)$ & $1(0.9)$ & $66(62.3)$ & & \\
\hline \multicolumn{7}{|c|}{ Do you know any sand fly prevention methods? } \\
\hline I don't know & $32(21.5)$ & 16(10.7) & $7(4.7)$ & $94(63.1)$ & \multirow[t]{2}{*}{10.59} & \multirow[t]{2}{*}{0.014} \\
\hline Yes & $82(31.7)$ & 43(16.6) & 13(5) & $121(46.7)$ & & \\
\hline \multicolumn{7}{|c|}{ What types of treatment for $\mathrm{CL}$ do you know? } \\
\hline Traditional & $76(26.9)$ & $39(13.8)$ & $13(4.6)$ & $155(54.8)$ & \multirow[t]{4}{*}{22.93} & 0.028 \\
\hline Modern & $21(52.5)$ & $5(12.5)$ & $3(7.5)$ & $11(27.5)$ & & \\
\hline I don't know & 15(21.4) & $11(15.7)$ & $2(2.9)$ & $42(60)$ & & \\
\hline Others & $1(11.1)$ & $2(22.2)$ & $1(11.1)$ & $5(55.6)$ & & \\
\hline What is your best treatment optio & & & & & & \\
\hline Modern drugs & $41(36)$ & $22(19.3)$ & $8(7)$ & $43(37.7)$ & 14.59 & 0.024 \\
\hline Traditional drugs & $51(24.3)$ & $26(12.4)$ & $9(4.3)$ & 124(59) & & \\
\hline I don't know & $22(26.2)$ & $11(13.1)$ & $3(3.6)$ & $48(57.1)$ & & \\
\hline
\end{tabular}

the prevention of CL. preventive measures. For prevention of sand fly bites, majority $149(36.5 \%)$ did not know of any prevention methods while only 53(12.9\%) and 37(9.1\%) considered hygiene and closing of windows and doors as prevention methods from sand fly bites (Table 5).

\section{Discussion}

In 2014, the World Health Organisation stressed the serious and increasing threat of vector-borne diseases in the world including leishmaniasis with a slogan "Small bite, big threat" [18]. Hence, there is a need for intensified research to understand the knowledge, attitude and practices of 
Table 4 Association between the knowledge of $C L$ and attitude towards treatment and residence among residents in $C L$ endemic areas in North West Ethiopia

\begin{tabular}{|c|c|c|c|c|}
\hline \multirow[t]{2}{*}{ Question/responses } & \multicolumn{2}{|l|}{ Residence } & \multirow[t]{2}{*}{$x^{2}$} & \multirow[t]{2}{*}{$P$-value } \\
\hline & Urban n(\%) & Rural n(\%) & & \\
\hline \multicolumn{5}{|l|}{ Have you ever seen a patient with CL? } \\
\hline No & $24(48)$ & $26(52)$ & 23.53 & 0.000 \\
\hline Yes & $64(17.9)$ & 294(82.1) & & \\
\hline \multicolumn{5}{|l|}{ Have you ever heard of sand fly? } \\
\hline No & $73(22.7)$ & 248(77.3) & 1.224 & 0.269 \\
\hline Yes & $15(17.2)$ & $72(82.8)$ & & \\
\hline \multicolumn{5}{|l|}{ Do sand flies transmit $\mathrm{CL}$ ? } \\
\hline No & $28(25.7)$ & $81(74.3)$ & 13.58 & 0.01 \\
\hline Yes & $33(15.1)$ & 186(84.9) & & \\
\hline I don't know & 27(33.8) & $53(66.2)$ & & \\
\hline \multicolumn{5}{|l|}{ How is CL transmitted? } \\
\hline I don't know & 43(31.4) & $94(68.6)$ & 22.8 & 0.008 \\
\hline Direct contact and air droplets & 14(31.8) & $30(68.2)$ & & \\
\hline Sand fly & 18(19.4) & 75(80.6) & & \\
\hline Mosquitoes & $4(16.7)$ & $20(83.3)$ & & \\
\hline Other means & $9(8.2)$ & 101(91.8) & & \\
\hline \multicolumn{5}{|l|}{ Is $\mathrm{CL}$ a serious disease? } \\
\hline No & $3(15)$ & $17(85)$ & 10.94 & 0.004 \\
\hline Yes & $65(19.3)$ & 272(80.7) & & \\
\hline I don't know & 20(39.2) & $31(60.8)$ & & \\
\hline \multicolumn{5}{|l|}{ Is CL a treatable disease? } \\
\hline No & $8(7.8)$ & $94(92.2)$ & 15.77 & 0.000 \\
\hline Yes & $55(27.5)$ & $145(72.5)$ & & \\
\hline I don't know & 25(23.6) & $81(76.4)$ & & \\
\hline \multicolumn{5}{|l|}{ Are there sand fly prevention methods? } \\
\hline Yes & $46(17.8)$ & 213(82.2) & & \\
\hline I don't know & $42(28.2)$ & 107(71.8) & 6.079 & 0.014 \\
\hline \multicolumn{5}{|l|}{ What types of treatment for $\mathrm{CL}$ do you know? } \\
\hline Traditional medicines only & $49(17.3)$ & $234(82.7)$ & 19.12 & 0.001 \\
\hline Modern medicines only & $7(17.5)$ & $33(82.5)$ & & \\
\hline I do not know & $24(34.3)$ & $46(65.7)$ & & \\
\hline Both traditional and modern medicines & $3(50)$ & $3(50)$ & & \\
\hline Others & $5(55.6)$ & $4(44.4)$ & & \\
\hline \multicolumn{5}{|l|}{ What is your best treatment option? } \\
\hline Modern medicines & $29(25.4)$ & $85(74.6)$ & 9.636 & 0.008 \\
\hline Traditional medicines & $33(15.7)$ & $177(84.3)$ & & \\
\hline I don't know & $26(31)$ & $58(69)$ & & \\
\hline
\end{tabular}

communities living in the endemic areas about CL. We found most participants had seen CL and knew its clinical manifestations. Similar findings had earlier been reported in Ochello, southern Ethiopia [19]. Our findings on the community's knowledge of CL are however better than reports from India where respondents recognised pictures of CL shown to them but did not have any lay perceptions about the disease $[20,21]$. These differences could be due to differences in the approach to socio-cultural factors and prevention strategies between countries. 
Table 5 Practice of respondents towards prevention of $C L$ in northwest, Ethiopia

\begin{tabular}{lll}
\hline Practice description & Frequency & Percent (\%) \\
\hline What are the prevention measures for cutaneous leishmaniasis? \\
Health education & 76 & 18.6 \\
Hygiene & 171 & 41.9 \\
Bed net & 129 & 31.6 \\
Insecticide & 58 & 14.2 \\
I don't know & 108 & 26.5 \\
Which sand fly prevention methods do you know? & \\
Ointment & 5 & 1.2 \\
Insecticides & 53 & 12.9 \\
Closing door and windows & 37 & 9.1 \\
Hygiene & 122 & 29.9 \\
Other & 42 & 10.3 \\
I don't know & 149 & 36.5 \\
\hline
\end{tabular}

\section{Knowledge on $\mathrm{CL}$ and its transmission}

Knowledge on CL and involvement of sand flies had a significant correlation with implementation of sand fly control measures in Guatemala [22] and Colombia [23]. Knowledge on the disease resulted in behaviour directed towards its prophylaxis and treatment [24]. We observed gaps in the knowledge on the transmission of the disease and still there are people in the community who believe that the parasite is transmitted via mosquitoes and through direct contact with infected persons. Though our findings are lower than 37.5 and $59.7 \%$ in a study in India where respondents claimed the role of mosquitoes in the transmission of CL and direct transmission from one person to another through direct contact respectively [20], such beliefs need to be addressed and correct information provided to communities in order to reduce potential for stigmatisation of affected individuals.

The transmission cycle of Leishmania exhibits characteristics that are particular to each endemic area therefore, does not allow extrapolation of data from one region to another [25]. In this study some significant proportions of the respondents did not have the correct knowledge on the peak season and time when the insects (sand fly) bite. These results are consistent with the report in Pakistan where $54.8 \%$ of the participants were unaware of the time when the insect bites and $24.8 \%$ believed that the peak season for sand fly bites was summer [14]. In most endemic areas, the transmission of the disease is almost throughout the year peaking after rainy season. Understanding the period of the year and the period of the day when transmission is highest is important for communities to prepare themselves by putting in place necessary preventive measures.
Perception and attitude towards CL and its treatment Studies have indicated a direct relationship between the knowledge of the population at risk of a disease and preventive measures [10]. In this study, majority of the participants believed that CL is a serious condition and were concerned about the cosmetic and disability consequences of the diseases. These findings are higher than those reported in Paraguay where only $10 \%$ of the participants perceived that CL was a problem [26]. Residence in rural areas significantly correlated with having seen a patient with CL, knowledge, attitude and practices about CL. Applying the Integrated Behaviour Model [27] which is grounded on the theory that an individual's intention to engage in a behaviour is influenced by his/ her attitude (experiential) towards the behaviour, our study indicates that high incidence, serious consequences of the disease and socioeconomic are key factors which have influenced concerns among rural residents about CL as presented with a significant association between rural residence and CL.

Usually CL heals spontaneously but in delayed treatment the disease can lead to serious tissue damage, secondary infection, disfiguring scar formation, impaired function and psychosocial consequences including depression. Delay in seeking treatment is associated with negative perceptions and attitude towards treatment options and lack of or inadequate information access about CL treatment have influence on the people's treatment seeking behaviour $[15,19]$. In many developing countries traditional healers play an important role in the delivery of health care and majority of the populations depend on them for most of their ailments [28]. We found that respondents believed CL is treatable and traditional medication was the best treatment option over modern treatment. Participants expressed positive experiential attitude towards traditional medicine because of its easy accessibility and expressed negative experiential attitude towards modern treatment because it is not easily accessible and the places where modern medicines can be accessed are far from the communities. A report on the review on various countries have suggested that traditional healers if properly trained can contribute positively to the primary health care teams and recommendations were made to take advantage of traditional healers as valuable resources to provide relevant and appropriate information and timely treatment in order to reduce consequences of delayed treatment of CL [29]. The government and other stakeholders involved in the provision of health services in Ethiopia should therefore bring the services closer to the affected populations by introducing mobile clinics, constructing health facilities in the endemic areas, making medications available at no or reduced cost and raising awareness of the community of the advantages of using modern treatment. Similarly, providers of health care in 
the affected areas should engage with traditional healers and determine effective ways of integrating traditional healers in the provision of care.

\section{Perceptions on $\mathrm{CL}$ prevention and control}

Most participants believed that CL is preventable and the most preferred preventive approach was personal hygiene. Education on CL and its consequences has been reported to be cost-effective and improves uptake of preventive measures [30]. In that regard, primary prevention like health education should be given priority through identification of population groups at risk including those involved in activities without using protection either by insecticides or clothing [31, 32]. On the use of bed nets, communities need to be educated that since sand flies are much smaller than mosquitoes impregnated bed nets with much smaller maze should be used. In addition, communities should be informed on how to reduce the natural reservoirs of Leishmania.

The epidemiology of leishmaniasis is influenced by several factors including suitable vectors, environmental conditions, socio-economic status, demographic and human behaviours [33, 34]. Poor housing, migration in search for employment, deforestation, immunosuppressive conditions like HIV and AIDS and malnutrition are some of the risk factors implicated on the prevalence of leishmaniasis [35, 36]. Like in many developing countries, these factors are also prevalent in Ethiopia. The country therefore, should put in place coordinated prevention, control and eradication programmes that would reduce public health and socio-economic impact of the disease to communities in endemic areas. The media including television, radio stations, printed media and political platforms should intensify raising community awareness on $\mathrm{CL}$ and because of the strong beliefs communities have on traditional medicine, the government should attempt to authenticate traditional healers and research should be carried out to determine the efficacy and safety of traditional medicines used to treat CL.

\section{Limitations}

Limitations of this study include limited number of open ended question which would have helped the respondents to add more information to the provided questions, and the findings may not necessarily be generalizable to the whole country because of differences in the population dynamics like environment, economy, and educational status. In addition, immunosuppression and co-morbidity could influence the manifestation and severity of the diseases.

\section{Conclusion}

This study has shown the knowledge gaps about CL which have contributed to negative experiential attitude and perceived control towards modern medicines. Inaccessibility and long distances from where modern treatment for $\mathrm{CL}$ is provided have reinforced positive experiential attitude towards traditional medicine. This information is valuable and should be used as indicators for awareness campaigns, health education, health promotion, future research on the disease and for designing appropriate policies to guide the government and community efforts against CL in endemic communities. School should feature prominently in the campaign by developing training curricula that provide children and communities with correct information on CL.

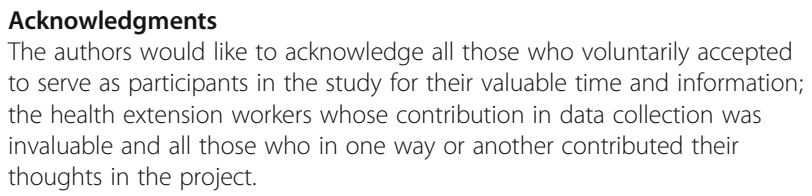

\section{Authors' contributions}

This report is part of a dissertation by HFT who conceived the project idea, wrote the draft proposal, applied for ethical clearance, collected data, analysed data and wrote the manuscript. YJM supervised HFT during inception of the proposal, reviewed and edited the proposal, assisted in interpretation of the results and writing the manuscript. RM assisted in data collection, analysis and interpretation of results and reviewing the manuscript and GTT co-supervised, reviewed and edited the project proposal and manuscript. All authors have critically read and reviewed and approved the manuscript for publication.

\section{Authors' information}

HFT is a general practitioner, academic staff and researcher at the University of Gondar, Ethiopia. She holds MD and MPH degrees. YJM is a professor of medical physiology and holds $\mathrm{MD}$ and $\mathrm{PhD}$ degrees. He is an associate Researcher at the University of South Africa and International Global Health Scholar, Centre for Global Health, University of Pennsylvania, USA. RM is a general practitioner, academic staff and researcher at the University of Gondar, Ethiopia and GTT is a professor, director and academic staff at the Department of Health Studies, University of South Africa.

\section{Funding}

This project was supported financially by the Institute of Tropical Medicine, Belgium and the University of Gondar, Ethiopia.

\section{Availability of data and materials}

The datasets used and/or analysed during this study are available from the Corresponding Author on reasonable request.

\section{Ethics approval and consent to participate}

The study was granted ethical clearance (REC-012714-039) by the Research Ethics Committee, Department of Health Studies, University of South Africa and permission to conduct the study in Ethiopia (O/N/P/ RCS/05/57) was granted by the Research and Publication Directorate, University of Gondar. Participation in the study was voluntary and written Informed Consent was obtained from all participants before commencement of the study and after the purpose and methods were clearly explained to them.

Consent for publication Not Applicable

Competing interests

The authors declare that they have no competing interests. 


\section{Author details}

${ }^{1}$ Department of Health Studies, University of South Africa, Pretoria, South Africa. ${ }^{2}$ Leishmaniasis Research and Treatment Centre, University of Gondar, Gondar, Ethiopia. ${ }^{3}$ Faculty of Medicine, University of Botswana, Gaborone, Botswana.

Received: 9 May 2019 Accepted: 24 September 2019

Published online: 16 October 2019

\section{References}

1. McGwire BS, Satoskar AR. Leishmaniasis: clinical syndrome and treatment. QJM. 2014;107(1):7-14. https://doi.org/10.1093/qjmed/htc116.

2. Bailey MS, Lockwood DN. Cutaneous leishmaniasis. Clin Dermatol. 2007; 25(2):203-11. https://doi.org/10.1016/j.clindermatol.206.05.

3. Hepburn NC. Cutaneous leishmanisis: current and future management. Expert Rev Anti Infec Ther. 2003;1(4):563-70 PMID: 15482153.

4. Martins AL, Barreto JA, Lauris JR, Martins AC. American tegumentary leishmanisis: correlations and immunological, histopathological and clinica parameters. An Bras Dermatol. 2014;89(1):52-8. https://doi.org/10.1590/ abd1806-4841.20142226.

5. World Health Organization. Country profiles: Ethiopia, 2014. Available: http://www.who.int/leishmaniasis/resources/Leishmaniasis_cp_Ethiopia_2 014_updated.pdf?ua=1. Accessed 15 Mar 2018.

6. Ayelaw A. Leishmaniasis in Ethiopia: a systematic review and met-analysis of prevalence in animals and humans. Heliyon. 2018:4:e00732. https://doi.org/ 10.1016/j.heliyon.2018.e00723.

7. Ferede G, Diro E, Getie S, Getnet G, Takele Y, Amsalu A, Wondimeneh Y. Visceral leishmaniasis-malaria coinfection and their associated factors in patients attending Metema Hospital, northwest Ethiopia: suggestion for integrated vector management. Malar Res Treat. 2017;2017:6816913.

8. Welay GM, Alene KA, Dachew BA. Visceral leishmanisis treatment and outcome and its determinants in Northwest Ethiopia. Epidemiol Health. 2016:39:e2017001. https://doi.org/10.4178/epih.e2017001.

9. van Griensven J, Gadisa E, Aseffa A, Hailu A, Beshah AM, Diro E. Treatment of cutaneous leishmaniasis caused by Leishmania aethiopica: a systematic review. PLoS Negl Trop Dis. 2016;10(3):e0004495. https://doi.org/10.1371/ journal.pntd.0004495.

10. Morrone A, Pitidis A, Pajno MC, Dassoni F, Latin O, Padovese V. Epidemiological and geographical aspects of leishmaniasis in Tigray northern Ethiopia: a retrospective analysis of medical records, 2005-2008. Trans R Soc Trop Med Hyg. 2011;105:273-80 Elsevier.

11. Goto H, Lauletta Lindoso AJ. Cutaneous and mucocutaneous leishmaniasis. Infect Dis Clin North Am. 2012;26(2):293-307. https://doi.org/10.1016/j.idc. 2012.03.001 Elsevier.

12. Bennis I, Thys S, Filali H, De Brouwere V, Sahibi H, Boelaert M. Psychosocial impact of scars due to cutaneous leishmaniasis on high school students in Errachidia province, Morocco. Infect Dis Poverty. 2017;6:46. https://doi.org/ 10.1186/s40249-017-0267-5 Bennis.

13. Okwor I, Uzonna J. Social and economic burden of human leishmaniasis. Am J Trop Med Hyg. 2016;94(3):489-93. https://doi.org/10.4269/ajtmh.15-0408.

14. Akram A, Ali Khan HA, Qadir A, Sabi AM. A cross-sectional survey of knowledge, attitude and practice related to cutaneous leishmaniasis and sand flies in Punjab, Pakistan. PLoS One. 2015;10(6):e0130929. https://doi. org/10.1371/journal.pone.0130929.

15. Fikre H, Mohammed R, Atinafu S, Griensven JV, Diro E. Clinical features and treatment response of cutaneous leishmaniasis in North-West Ethiopia. Trop Med Int Health. 2017;22(10):1293-301. https://doi.org/10.1111/tmi.12928.

16. Fedral Democratic Repubilc of Ethiopia. 2018. ethiopia.gov.org FDRE Etiopia goverment Portal. Available at: http://www.ethiopia.gov.et/amhara-regionalstate. Accessed 13 May 2018.

17. Ethiopia Demographic Health Survey (EDHS) 2011. Central Statistical Agency/Ethiopia and ICF International. Available: http://dhsprogram.com/ pubs/pdf/FR255/FR255.pdf. Accessed Apr 2019.

18. World Health Organisation. Cutaneous leishmaniasis: In selected countries of WHO Eastern Mediterranean and African Regions. Report on an Interregional Network meeting. Casablanca, Morocco. WHO/HTM/NTD/IDM/2015.

19. Kebede N, Worku A, Ali A, Animut A, Negash Y, Gebreyes WA, Satoskar A. Community knowledge, attitude and practice towards cutaneous leishmaniasis endemic area Ochello, Gamo Gofa Zone, South Ethiopia. Asian Pac J Trop Biomed. 2016;6(7):562-7. https://doi.org/10.1016/j.apjtb.2016.01.018 Elsevier.
20. Nadha B, Srinivasan R, Jambulingam P. Cutaneous leishmaniasis: knowledge, attitude and practices of the inhabitants of the Kani forest tribal settlements of Tiruvananthapuran district, Kerala, India. Health Educ Res. 2014;29(6): 1050-7. https://doi.org/10.1093/her,cyu064.

21. Simi SM, Anish TS, Jyoti R, Vijayakumarr K, Philip RR, Paul N. Searching for cutaneous leishmaniasis in tribal from Kerala, India. J Global Infect Dis. 2010; 2(2):95-100. https://doi.org/10.4103/0974-777X.62874.

22. Arana BA, Rizzo NR, Navin TR, Klein RE, Kroeger A. Cutaneous leishmaniasis in Guatemala: people's knowledge, concepts and practices. Ann Trop Med Parasitol. 2000;94(8):779-86. https://doi.org/10.1080/00034983.2000.11813602.

23. Pardo RH, Carvajal A, Ferro C, Davies CR. Effect of knowledge and economic status on sandfly control activities by householders at risk of cutaneous leishmaniasis in the sub-Anden region of Huila Department, Colombia. Biomedica. 2006;26(Supl 1):167-9.

24. Vazquez ML, Kroeegr A, Lipowsky R, Alzate A. Popular conceptions regarding cutaneous leishmaniasis in Colombia and their applicability in control programmes. Bol Officina Sanit Panam. 1991;110(5):402-12.

25. Ruoti M, Oddone R, Lampert N, Orué E, Miles MA, Alexander N, Rehman AM, Njord R, Shu S, Brice S, Sinclair B, Krentel A. Mucocutaneous leishmaniasis: knowledge, attitudes and practices among Paraguayan communities, patients and health professionals. J Trop Med. 2013;2013: 538629. https://doi.org/10.1155/2013/538629.

26. Membrive NA, Rodrigues G, Gualda KP. Environmental and animal characteristics as factors associated with American cutaneous leishmaniasis in rural locations with presence of dogs, Brazil. PloS One. 2012;7:e47050. https://doi.org/10.1371/journal.pone.0047050.

27. Montano DE, Kasprzyk D. Theory of reasoned action, theory of planned behaviour, and the integrated behaviour model. Health Behav. 2015;70(4):231.

28. Okeke TA, Okafor HU, Uzochukwu BS. Traditional healers in Nigeria: perception of cause, treatment and referral practices for severe malaria. J Biocos Sci. 2006;38:491-500.

29. Hoff W. Traditional healers and community health. World Health Forum. 1992;13:182-7.

30. Saberi S, Zamani A, Motamedi N, Nilforoushzadeh MA, Jaffary F, Rahimi E, et al. The knowledge of students regarding cutaneous leishmaniasis in the hyperendemic region of Shahid Babaie Airbase. Vector Borne Zoonotic Dis. 2012;12(4):306-9. https://doi.org/10.1089/vzb.2010.0259.

31. Votypka J, Kasap OE, Volf P, Alten B. Risk factors for cutaneous leishmaniasis in Cukurova region, Turkey. Trans Royal Soc Trop Medi Hyg. 2012;106(3): 189-90. https://doi.org/10.1016/j.trstmh.2011.12.004.

32. Stockdale L, Newton R. A review of preventive methods against human leishmaniasis infection. PLoS Neg trop Dis. 2013;7(6):e2278. https://doi.org/ 10.1371/journal.pntd.0002278.

33. Oryan A, Akbari M. Worldwide risk factors in leishmaniasis. Asian Pac J Trop Med. 2016;9(10):925-32. https://doi.org/10.1016/j.apjtm.2016.06.021.

34. Ali N, Ullah A, Wahid S, Khishroon M, Rasheed SB. Distribution, species composition and relative abundances of sandfies in North Waziristan. Med Vet Entomol. 2016;30(1):89-94. https://doi.org/10.1111/mve.12141 Agency, Pakistan.

35. Alvar J, Yactayo S, Bern C. Leishmainasis and poverty. Trends Parastol. 2006; 22(12):552-7. https://doi.org/10.1016/j.pt.2006.09.004.

36. Bailey F, Mondragon-Shem K, Haines RL, Olabi A, Alorfi A, Ruiz-Postigo JA, Alvar J, Hotez P, Adams ER, Velez ID, Al-Salem W, Eaton J, Acosta-Serraw A Molyneux DH. Cutaneous leishmaniasis and co-morbid major depressive disorder: a systematic review with burden estimates. PLoS Negl Trop Dis. 2019;13(2):e0007092 https://doi.org/10.1371/journal.

\section{Publisher's Note}

Springer Nature remains neutral with regard to jurisdictional claims in published maps and institutional affiliations. 